\title{
-Review-
}

\section{In Vitro Production of Blastocyst and Embryo Transfer in Mammals}

\author{
Kiyohiko Takagishi ${ }^{1 *}$, Kenji Momozawa ${ }^{1}$ and Yoshinori Fukuda ${ }^{1}$ \\ ${ }^{1}$ School of Veterinary Medicine and Animal Sciences, Kitasato University, Towada, Aomori 034- \\ 8628, Japan
}

Embryo transfer is the comprehensive technology that includes recovery of fertilized eggs, in vitro embryo culture, embryo preservation and transfer of embryos. It was developed in laboratory animals at the beginning of application. After the 1980, these techniques were applied to farm animals, and now the embryo transfer technique is important in livestock production. Embryo transfer is especially indispensable technology for low cost livestock production and effective application of superior gene resources. Recently, the embryo transfer technique has also become important in producing transgenic and clone animals, so efforts are continuing to aim at the efficient production of offspring.

\section{Overview of Embryo Transfer in Mammals}

The first successful transfer of mammalian embryos was performed in rabbits in 1890 [1]. At present, embryo transfer in laboratory animals is successfully performed in mice [2], rats [3], hamsters [4], guinea pigs, gerbils [5] and various other species. Conception was also obtained in farm animals such as sheep [6] and cattle [7].

Embryo transfer procedures are able to be divided into oviduct transfer and uterus transfer mainly by the transfer site. We decide which procedure should be used according to the developmental stage of the embryos. In general, it is important that the developmental age of embryos is the same as or advances the pregnancy date of the recipient female. When the synchrony of the embryo and uterus is decreased, the pregnancy rate will decline.

In embryo transfer in mice and rats, the pseudopregnant female was used as a recipient.

Received: December 24, 2002

Accepted: February 20, 2003

*To whom correspondence should be addressed.

e-mail:kyo@vmas.kitasato-u.ac.jp
Generally, embryos at less than 8-cell stage were transferred to the oviduct, and morula or later stage embryos were transferred to the uterus. But it is possible to transfer embryos of all stages from 1-cell to blastocyst stage embryos to the oviduct in mice. For both procedures, $50-75 \%$ of embryos will develop to term [8].

Hamster embryos were transferred in the same way as mouse embryos. Embryos were transferred into the oviducts or uterus of the pseudopregnant female [9], and were also transferred even into the ovarian bursa [10]. In hamster, it is extremely difficult to obtain offspring, because the embryo is very sensitive in a culture environment and embryonic development is hardly observed in vitro when embryos are operated on for a long time. Therefore, embryos should be transferred into the reproductive tract of a pseudopregnant female as soon as possible. Although embryo transfer of in vivo fertilized hamster eggs succeeded in 1964 [4], successful embryo transfer of in vitro fertilized oocytes was not achieved until 1992 [11], because of difficulty in culturing embryos in vitro.

Embryo transfer in the pig is generally carried out with a surgical method and embryos are transferred to the oviduct or uterine horn. It is known that to some extent of porcine embryos are required to be implanted and develop to term normally, and it assumed that at least 4 embryos are required in porcine embryo transfer. The reproductive tract of the anesthetized recipient female is exteriorized via midventral laparotomy, and embryos are directly transferred to the desired location. Nevertheless, a non-surgical procedure for embryo transfer is preferable to a surgical procedures from the point of view of animal welfare, and also because the procedure can be performed without the need for special equipment and skills. Litters have been reported after transcervical transfer of pig embryos, and live offspring have also been produced after endoscopic 
transfer. Thereafter, pregnancy was reported in the case of embryos that were transferred by a non-surgical method in some laboratories [12-17].

In cattle, embryos were directly transferred to the surgically exteriorized uterus, in the early period, but now it is usual to transfer the embryos, developed to the morula or later stages, to the inside of the uterus through the cervix non-surgically by using equipment similar to that for artificial insemination. To archive a high pregnancy rate, it is important that the egg should be placed within the uterine horn ipsilateral to the corpus luteum, because surgical transfer to the contralateral horn has resulted in poor embryo survival [18-20]. It could be the result that the embryo in the contralateral horn is not possible to prevent luteolysis continually $[21,22]$.

\section{Evaluation of the Embryo Quality}

The quality evaluation of the embryo prior to embryo transfer is important to the success of embryo transfer. Hitherto, the quality of the embryo has been evaluated by its morphological structure. It is known that the developmental competence of the early embryo is correlated to the normality of their morphology and practically evaluated by using the grading system of their morphological quality at the blastocyst stage. The blastocyst, which has a fine morphology, has been judged as a fine embryo. Morphological evaluation of embryos is useful in predicting pregnancy rates for groups of embryos, but it is less useful in determining the survival of individual embryos [23]. In some cases, morphologically poor-quality embryos produced pregnancies, whereas apparently good embryos failed to result in pregnancy [24]. These facts suggest that criteria other than morphological ones are needed to evaluate the viability of embryos.

Predicting embryo viability and developmental potential from metabolic characteristics has been reported to be superior to morphological criteria. Oxygen consumption of preimplantation embryos is an important factor that may provide valuable information on metabolic processes and subsequent viability of the embryos. The relationship between the quality of the blastocyst and oxygen consumption is studied [25, 26]. Oxygen consumption of an individual embryo in early developmental stages is correlated with the subsequent development of the embryo. The morula stage embryo with lager oxygen consumption has strong potentiality for further development into a hatched blastocyst.

Recently, Houghton et al. [27] investigated the amino acid metabolism by a non-invasive measurement technique. They reported that there is a remarkable difference in amino acid turnover between embryos that develop to the blastocyst stage and those that arrest prior to blastocyst formation, and showed the potential to select developmentally competent single human embryos with amino acid metabolism as an indicator.

In addition to the above, the consumption of glucose and pyruvate could be used as an indicator to evaluate the developmental competence of single embryos. Unfortunately, there are few reports that have examined these types of consumption in individual embryos.

\section{In Vitro Embryo Culture and Growth Abnormalities}

Generally, culture medium containing fetal bovine serum or heat-inactivated human serum is used for in vitro culture of mammalian embryos. It is known that embryo culture with a serum-supplemented medium resulted in large offspring syndrome, which is associated with prolonged gestation length in cattle and sheep [28-31]. It also resulted in a higher perinatal death rate after embryo transfer, especially when IVM/ IVF derived embryos were cultured under aberrant conditions in vivo or co-cultured with somatic cells in vitro [29, 32]. The large offspring syndrome has not been reported in human, mice or any other species as a result of in vitro embryo manipulation. Young et al. [33] suggested that these differences might be due to intrinsic differences between these species and cattle and sheep, or to differences in protocols used. Although cattle and sheep embryos are usually transferred to recipients as blastocysts, human embryos have been returned to the mother at about the four-cell stage. Mouse embryos are cultured routinely to the blastocyst stage, but all commonly used media are serum-free.

The cause of these abnormalities of fetal development is not yet clear. Some investigators have suggested that endocrine changes in the fetus and altered expression of imprinted genes may be most likely to cause abnormal growth. The insulin-like growth factor (IGF) family modulates fetal growth. Relationships between circulating levels of IGF-I, not IGF-II, and fetal development have been identified in several species. But, based on the analysis of genetic mutants, it is clear that IGF-II also plays an important role in the regulation of fetal growth. Because the Igf-2 gene, encoding IGF-II, is expressed only from the paternal allele in most tissues [34], it is predicable that 
loss of imprinting of Igf-2 would enhance fetal growth.

Fetal overgrowth can also be associated with mutation of the $\mathrm{H} 19$ gene [35]. This imprinted gene encodes an untranslated RNA, and is located adjacent to the gene that encodes IGF-II (Igf-2). Expression of $H 19$ occurs coincident with the elimination of $/ g f-2$ transcription, consequently reducing production of IGFII mRNA [36]. Genetic knockout of the maternal H19 locus in mice is associated with a $27 \%$ increase in the size of offspring at birth. Although patterns of imprinting of the IGF-II ligand and its receptor (Igf-2r) have not been established for sheep and cattle embryos, the possibility exists that alterations in imprinting, and thus the expression of $\lg f-2, \lg f-2 r$ and $H 19$, may contribute to differences in the body weight of fetuses. Although allelic methylation of imprinted genes may occur during the preimplantation period, methylation of non-imprinted genes is not observed before implantation. This provides a basis for considering the susceptibility of imprinted genes to environmental influence in the preimplantation period.

\section{Production of Transferable Cattle Embryos In Vitro}

The conventional non-surgical recovery method for obtaining embryos from superovulated donor cows is costly. The approach to providing large numbers of embryos at lower cost is harvesting oocytes from ovarian follicles. The oocytes may be collected from the ovaries of slaughtered cattle or from selected live donors by aspiration via laparoscopic [37] or culdoscopic techniques [38]. They are matured and fertilized in vitro and then cultured until they reach a transferable stage, as morulae or blastocysts [39]. Establishment of the in vitro culture system that makes blastocysts by using follicular oocytes collected from ovaries of slaughtered females is directly associated with the embryo transfer industry and is effective in increasing the production efficiency of livestock. But the rate of blastocyst formation in the culture of in vitromatured and fertilized oocytes remains low at 30-40\% on average.

Oxygen tension is important for embryo development in vitro [40]. The oxygen concentration in female reproductive organs such as the oviduct and uterus is lower than the atmospheric concentration. The beneficial effect of reduced oxygen tension may be due to the decrease in reactive oxygen species within the embryo. Furthermore, the metabolic activity of embryos cultured under a low oxygen atmosphere correlated more closely with that of in vivo-derived embryos [41].

Lactate and pyruvate are the main energy substrates throughout the early stages of embryonic development. Glucose is harmful to the embryos at this stage, but embryos beyond the 8-cell stage can preferentially utilize glucose as an energy source $[42,43]$. Therefore, recently, the sequential culture system, using media suitable for each stage, has been examined.

When embryos are cultured without using a co-culture system, the experimental results are affected by the difference in the lot of serum or serum albumin (BSA) and reproducibility becomes low. Because the use of serum also carries a risk of microbial contamination, it is important to establish the embryo culture system with a chemically defined medium that contains neither serum nor BSA.

In mice, a simple medium named KSOM was successfully used for the culture of early embryos [44], but the replacement of the BSA in KSOM with polyvinylalcohol (PVA) was found to partially depress the rate of blastocyst formation and to severely inhibit hatching in vitro. The addition of amino acids to BSAfree KSOM was found to restore the rate of blastocyst formation and hatching $[45,46]$.

In rabbits, Carney and Foote [47] reported that the rate of blastocyst formation and hatching of the embryos cultured in vitro in protein-free RD medium (RPMI1640:DMEM=1:1) are similar to those in protein supplemented ordinary medium. They suggested that the high concentration of inositol in that medium promotes the development of rabbit embryos. We investigated the effect of the addition of RD medium to the m-KSOM medium on blastocyst formation and hatching in cattle embryos in vitro $[48,49]$. The addition of RD medium resulted in good embryonic development in vitro: $64 \%$ of embryos reached the blastocyst stage and $82.2 \%$ of them hatched. These results obtained were better than those of the control groups, but replacement of BSA in this medium with PVP brought about a decrease in the rate of both blastocyst formation and hatching.

Supplementation of inositol to the protein-free culture medium promoted the rate of blastocyst formation and hatching of the embryos in vitro is reported in rabbits [50], mice [51] and cattle [52]. When inositol was added to the KSOM/aa+RD medium for cattle embryos, the decline caused by the replacement of BSA with PVP was restored and we obtained the similar results with when we used the medium including BSA. We also investigated the freezing preservation ability and the ability to develop to a live calf of the blastocysts 
produced with the m-KSOM/aa+RD medium. After freezing and thawing, these embryos showed $80 \%$ or more viability. Most of the viable embryos hatched and show good developmental ability. The concentration of the RD medium that results in the best embryonic development was $20 \%$. Sixteen blastocysts (7 fresh and 9 frozen-thawed) of good quality developed in $\mathrm{m}$ $\mathrm{KSOM} / \mathrm{aa}+\mathrm{RD}$ were transferred non-surgically to 16 recipients. Ten of the 16 recipients became pregnant, and delivered 9 live calves.

\section{Conclusions}

For embryo transfer in livestock, the non-surgical transfer technique is the most desirable procedure because of low level of skill required and low cost. The establishment of a system that makes fine blastocysts in vitro efficiently is become needed. It is also necessary to consider the normality of the offspring. In some laboratory animals, such as mice, in vitro culture of the embryo is easily performed, but culture system development has not yet been completed for all animal species.

We developed the complete synthetic medium m$\mathrm{KSOM} / \mathrm{aa}+\mathrm{RD}$ that eliminated indefinite elements and have obtained fine blastocyst production and normal offspring in cattle by using this medium. Nevertheless, the embryo production efficiency is not sufficient for industrial usage, and more improvement of the medium and an increase in the number of the case is necessary.

\section{References}

1) Heape, W. (1890): Preliminary note on the transplantation and growth of mammalian ova within a uterine fostermother. Proc. R. Soc. Lond., 48, 457-458.

2) Fekete, E. and Little, C.C. (1942): Observations on the mammary tumor incidence of mice born from transferred ova. Cancer Res., 2, 525-530.

3) Nicholas, J.S. (1933): Development of transplanted rat eggs. Proc. Soc. Exp. Biol. Med., 30, 1111-1113.

4) Blaha, G.C. (1964): Effect of age of the donor and recipient on the development of transferred golden hamster ova. Anat. Rec., 150, 413-416.

5) Mochida, K., Wakayama, T., Takano, K., Noguchi, Y., Yamamoto, Y., Suzuki, O., Ogura, A. and Matsuda, J. (1999): Successful cryopreservation of mongolian gerbil embryos by vitrification. Theriogenology, 51, 171.

6) Moore, N.W. and Shelton, J.M. (1964): Egg transfer in sheep. J. Reprod. Fert., 7, 145-152.

7) Rawson, L.E.A., Lawson, R.A.S., Moor, R.M. and Baker, A.A. (1972): Egg transfer in the cow: Synchronization requirements. J. Reprod. Fert., 28, 427-431.
8) Hogan, B., Beddington, R., Costantini, F. and Lacy, E. (1994) Manipulation the Mouse Embryo: A Laboratory Manual. Cold Spring Harbor Laboratory Press, New York.

9) Sato, E. and Yanagimachi, R. (1972): Transplantation of preimplantation hamster embryos. J. Reprod. Fert., 30, 329-332.

10) Ogura, A, Matsuda, J., Asano, T. and Yanagimachi, R. (1995): Birth of pups after intra-ovarian bursal transfer of hamster zygotes. J. Reprod. Dev., 41, 339-343.

11) Barnett, D.K. and Bavister, B.D. (1992): Hypotaurine requirement for in vitro development of golden hamster one- cell embryos into morulae and blastocysts, and production of term offspring from in vitro-fertilized ova. Biol. Reprod., 47, 297-304.

12) Reichenbach, H.D., Modl, J. and Brem, G. (1993): Piglets born after transcervical transfer of embryos into recipient gilts. Vet. Rec., 133, 36-39.

13) Galvin, J.M., Killian, D.B. and Stewart, A.N.V. (1994): A procedure for successful nonsurgical embryo transfer in swine. Theriogenology, 41, 1279-1289.

14) Li, J., Rieke, A., Day, B.N. and Prather, R.S. (1996): Technical note: Porcine nonsurgical embryo transfer. J. Anim. Sci., 74, 2263-2268.

15) Yonemura, I., Fujino, Y., Irie, S. and Miura, S. (1996) Transcervical transfer of porcine embryos under practical conditions. J. Reprod. Dev., 42, 89-94.

16) Hazeleger, W. and Kemp, B. (2001): Recent developments in pig embryo transfer. Theriogenology, 56, 1321-1331.

17) Besenfelder, U., Modl, J., Muller, M. and Brem, G. (1997): Endoscopic embryo collection and embryo transfer into the oviduct and then uterus of pigs. Theriogenology, 47, 10511060.

18) Newcomb, R., Christie, W.B. and Rowson, L.E.A. (1978): Comparison of the fetal survival rate in heifers after the transfer of an embryo surgically to one uterine horn and non-surgically to the other. J. Reprod. Fert., 52, 395-397.

19) Newcomb, R., Christie, W. B. and Rowson, L.E.A. (1980): Fetal survival rate after the surgical transfer of two bovine embryos. J. Reprod. Fert., 59, 31-36.

20) Charistie, W.B., Newcomb, R. and Rowson, L.E.A. (1980): Non-surgical transfer of bovine eggs: Investigation of some factors affecting embryo survival. Vet. Rec., 106, 190-193.

21) Del Campo, M.R., Rowe, R.F., French, L.R. and Ginther, O.J. (1977): Unilateral relationship of embryos and the corpus luteum in cattle. Biol. Reprod., 16, 580-585.

22) Christie, W.B., Newcomb, R. and Rowson, L.E.A. (1979): Embryo survival in heifers after transfer of an egg to the uterine horn contralateral to the corpus luteum and the effect of treatments with progesterone or hCG on pregnancy rates. J. Reprod. Fert., 56, 701-706.

23) Linder, G.M. and Wright, R.W.Jr. (1983): Bovine embryo morphology and evaluation. Theriogenology, 29, 407-416.

24) Shea, B.F. (1981): Evaluating the bovine embryo. Theriogenology, 15, 31-42.

25) Overstrom, E.W. (1992): Manipulation of early embryonic development. Anim. Reprod. Sci., 28, 277-285.

26) Shiku, H., Shiraishi, T., Ohya, H., Matue, T., Abe, H., 
Hoshi, H. and Kobayashi, M. (2001): Oxygen consumption of single bovine embryos probed by scanning electrochemical microscopy. Anal. Chem., 73, 3751-3758.

27) Houghton, F.D., Hawkhead, J.A., Humpherson, P.G., Hogg, J.E., Balen, A.H., Rutherford, A.J. and Leese, H.J. (2002): Non-invasive amino acid turnover predicts human embryo developmental capacity. Hum. Reprod., 17, 9991005 .

28) Walker, S.K., Heard, T.M. and Seamark, R.F. (1992): In vitro culture of sheep embryos without co-culture: Successes and perspectives. Theriogenology, 37, 111-126.

29) Holm, P., Walker, S. K. and Seamark, R.F. (1996): Embryo viability, duration of gestation and birth weight in sheep after transfer of in vitro matured and in vitro fertilized zygotes cultured in vitro or in vivo. J. Reprod. Fert., 107, 175-181.

30) Thompson, J.G., Gardner, D.K., Pugh, P.A., McMillan, W.H. and Tervit, H.R. (1995): Lamb birth weight is affected by the culture system utilized during in vitro preelongation development of ovine embryos. Biol. Reprod., 53, 1385-1391.

31) van Wagtendonk-de Leeuw, A.M., Aerts, B.J.G. and den Dass, J.H.G. (1998): Abnormal offspring following in vitro production of bovine preimplantation embryos: A field study. Theriogenology, 49, 883-894.

32) Behboodi, E., Anderson, G.B., BonDurant, R.H., Cargill, S.L., Kreuscher, B.R., Medrano, J.F. and Murray, J.D. (1995): Birth of large calves that developed from in vitroderived bovine embryos. Theriogenology, 44, 227-232.

33) Young, L.E., Sinclair, K.D. and Wilmut, I. (1988): Large offspring syndrome in cattle and sheep. Rev. Reprod., 3, 155-163.

34) DeChiara, T.M., Robertson, E.J. and Efstratiadis, A. (1991): Parental imprinting of the mouse insulin-like growth factor II gene. Cell, 64, 849-859.

35) Leighton, P.A., Ingram, R.S., Eggenschwiler, J., Efstratiadis, A. and Tilghman, S.M. (1995): Disruption of imprinting caused by deletion of the H19 gene region in mice. Nature, 375, 34-39.

36) Leighton, P.A., Saam, J.R., Ingram, R.S. and Tilghman, S.M. (1996): Genomic imprinting in mice: Its function and mechanism. Biol. Reprod., 54, 273-278.

37) Lambert, R.D., Sirard, M.A., Bernard, C., Beland, R., Rioux, J.E., Leclerc, P., Menard, D.P. and Bedoya, M. (1986): In vitro fertilization of bovine oocytes matured in vivo and collected at laparoscopy. Theriogenology, 25, 117-133.

38) Pieterse,M.C., Kappen, K.A., Kruip, Th.A.M. and Taverne, M.A.M. (1988): Aspiration of bovine oocytes during transvaginal ultrasound scanning of the ovaries. Theriogenology, 30, 751-762.
39) Gordon, I. and Lu, K.H. (1990): Production of embryos in vitro and its impact on livestock production. Theriogenology, $33,77-87$.

40) Bavister, B.D. (1995): Culture of preimplantation embryos: Fact and artifacts. Hum. Reprod. Update, 1, 91-148.

41) Hooper, K., Lane, M. and Gardner, D.K. (2001): Reduced oxygen concentration increases mouse embryo development and oxidative metabolism. Theriogenology, $55,334$.

42) Rosenkrans, C.F.Jr., Zeng, G.Q., McNamara, G.T., Schoff, P.K. and First, N.L. (1993) Development of bovine embryos in vitro as affected by energy substrates. Biol. Reprod., 49, 459-462.

43) Rieger, D., Loskutoff, N.M. and Betterrridge, K.J. (1992) Developmentally related changes in the metabolism of glucose and glutamine by cattle embryos produced and cocultured in vitro. J. Reprod. Fert., 95, 585-595.

44) Lawitts, J.A. and Biggers, J.D. (1993): Culture of preimplantaion embryos. Methods Enzymol., 225, 153164.

45) Ho, Y., Wigglesworth, K., Eppig, J.J. and Schultz, R.M. (1995): Preimplantation development of mouse embryos in KSOM: Augmentation by amino acids and analysis of gene expression. Mol. Reprod. Dev., 41, 232-238.

46) Biggers, J.D., Summers, M.C. and McGinnis, L.K. (1997): Polyvinyl alcohol and amino acids as substitutes for bovine serum albumin in culture media for mouse preimplantation embryos. Hum. Reprod. Update, 3, 125-135.

47) Carney, E.W. and Foote, R.H. (1991): Improved development of rabbit one-cell embryos to the hatching blastocyst stage by culture in a defined, protein-free culture medium. J. Reprod. Fert., 91, 113-123.

48) Momozawa, K. and Fukuda, Y. (1999): Effects of chemically defined medium m-KSOM/aa+RD and inositol in medium on development up to hatched blastocysts of bovine oocytes matured and fertilized in vitro. Proc. 95th. Jpn. Soc. Anim. Sci., p. 61 (in Japanese).

49) Momozawa, K. and Fukuda, Y. (2002): Effect of GlcNAc supplemented to chemically defined medium 20\% RD$\mathrm{mKSOM} / \mathrm{aa}$ on development of bovine embryos fertilized in vitro. Proc. 100 th Jpn. Soc. Anim. Sci., p. 121 (in Japanese).

50) Fahy, M.M. and Kane, M.T. (1992): Inositol stimulates DNA and protein synthesis, and expansion by rabbit blastocysts in vitro. Hum. Reprod., 7, 550-552.

51) Kane, M.T., Norris, M. and Harrison, R.A.P. (1992): Uptake and incorporation of inositol by preimplantation mouse embryos. J. Reprod. Fert., 96, 617-625.

52) Bredbacka, P. and Bredbacka, K. (1993): Effect of inositol on in vitro development of murine and bovine morulae and blastocysts. Theriogenology, 39, 195. 